\title{
Implementation of a Training Program to Improve the CRNA Precepting Experience at an Academic Medical Center
}

\author{
Megan Jean Gillespie \\ West Virginia University, gillespieme@mix.wvu.edu
}

Follow this and additional works at: https://researchrepository.wvu.edu/etd

Part of the Other Nursing Commons

\section{Recommended Citation \\ Gillespie, Megan Jean, "Implementation of a Training Program to Improve the CRNA Precepting Experience at an Academic Medical Center" (2022). Graduate Theses, Dissertations, and Problem Reports. 10168.}

https://researchrepository.wvu.edu/etd/10168

This Problem/Project Report is protected by copyright and/or related rights. It has been brought to you by the The Research Repository @ WVU with permission from the rights-holder(s). You are free to use this Problem/Project Report in any way that is permitted by the copyright and related rights legislation that applies to your use. For other uses you must obtain permission from the rights-holder(s) directly, unless additional rights are indicated by a Creative Commons license in the record and/ or on the work itself. This Problem/Project Report has been accepted for inclusion in WVU Graduate Theses, Dissertations, and Problem Reports collection by an authorized administrator of The Research Repository @ WVU. For more information, please contact researchrepository@mail.wvu.edu. 
Implementation of a Training Program to Improve the CRNA Precepting Experience at an Academic Medical Center

Megan Jean Gillespie, BSN, SRNA

Doctoral of Nursing Practice Project submitted to the School of Nursing

at West Virginia University

in partial fulfillment of the requirement for the degree of

Doctor of Nursing Practice in

Nurse Anesthesia

Aaron Ostrowski, DNP, CRNA, Chair

Eric J. Lindstrom, MSN, CRNA

Kesheng Wang, PhD, MA, BS

Department of Nursing

Morgantown, West Virginia

2021

Keywords: Preceptor Training Program, Comfort, Confidence, Students, New-Hires Copyright 2021 Megan Jean Gillespie 


\begin{abstract}
Implementation of a Training Program to Improve the CRNA Precepting Experience at an Academic Medical Center
\end{abstract}

\title{
Megan Jean Gillespie
}

Formal preceptorship training has been shown to improve the comfort and confidence with precepting across many disciplines. Currently, there is no training program in place for the Certified Registered Nurse Anesthetist (CRNA) preceptors at a large academic medical center in West Virginia. The overarching goal of this quality improvement (QI) project was to implement a formal preceptorship training for the CRNAs at the facility of interest. The training, or intervention, was the Preceptor Essentials Parts I and II on NetLearning. This project followed the pre-intervention-post-survey design. The participants were self-selected CRNAs. The survey results were analyzed using the Mann-Whitney $U$ test and descriptive statistics to evaluate the effectiveness and usefulness of this intervention. The participants showed a statistically significant improvement in satisfaction with their preparation for precepting $(\mathrm{p}=0.029)$. They also showed improvements with confidence in their ability to precept $(\mathrm{p}=0.629)$, comfort in actively coaching $(\mathrm{p}=0.337)$, and comfort in working with different personalities or learning styles than their own ( $\mathrm{p}=0.507)$, but not to a statistically significant amount. The results were borderline significant for improving confidence in providing feedback $(\mathrm{p}=0.067)$. All pretraining survey participants $(\mathrm{n}=19)$ denied having previous formal preceptor training. The posttraining survey participants $(\mathrm{n}=11)$ were all satisfied with the mode of learning, computer-based and self-paced. Although past studies have shown statistically significant improvements with preceptors' comfort and confidence following formal preceptorship training, this QI Project did not show all statistically significant improvements, but all areas did improve from the pre- to post-training surveys, supporting clinical significance. 


\section{Table of Contents}

Implementation of a Training Program to Improve the CRNA Precepting Experience at an Academic Medical Center...........................................................................................1

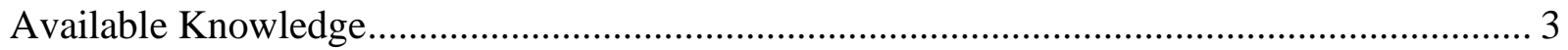

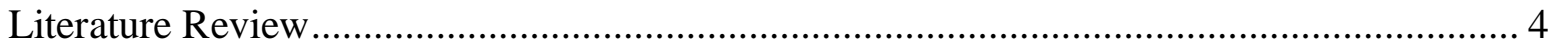

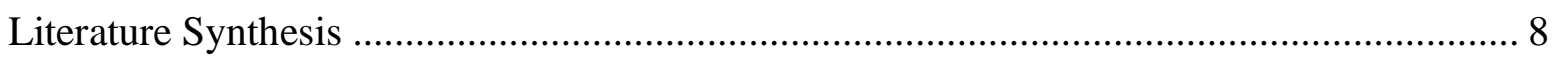

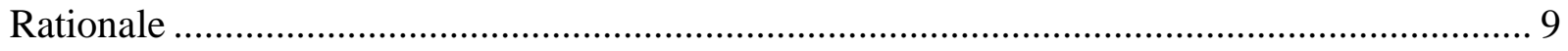

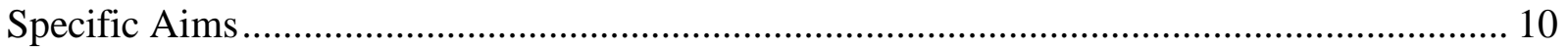

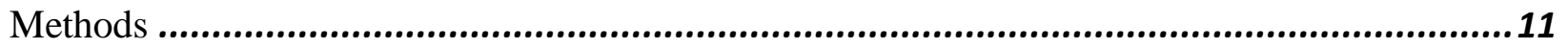

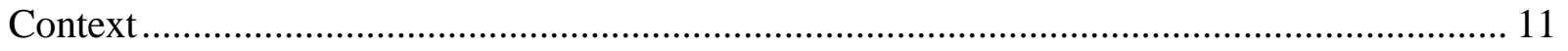

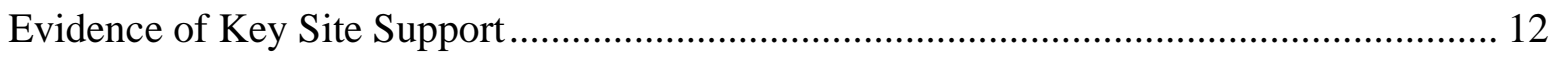

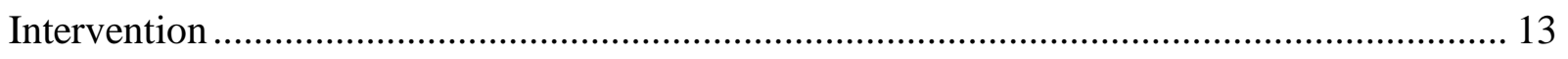

Benchmarks and gaps in evidence ................................................................... 15

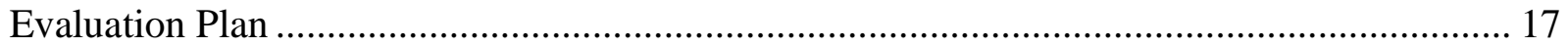

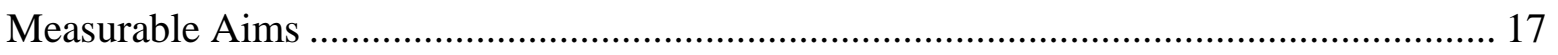

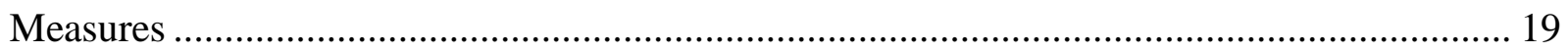

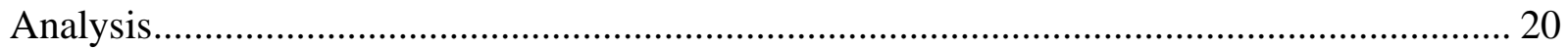

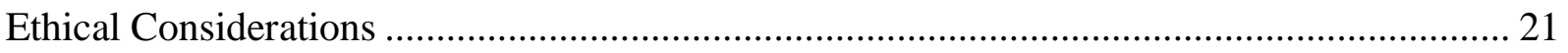

Results.......................................................................................................... 22

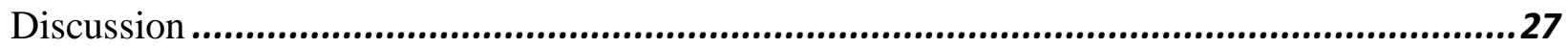

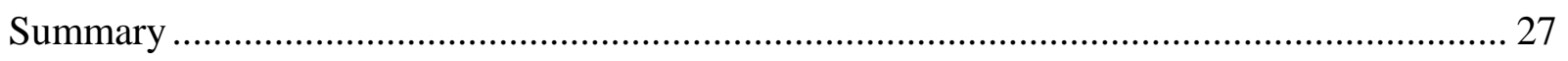

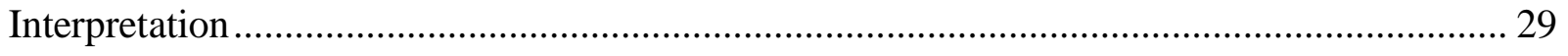

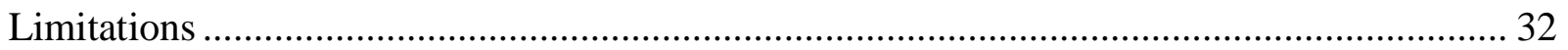

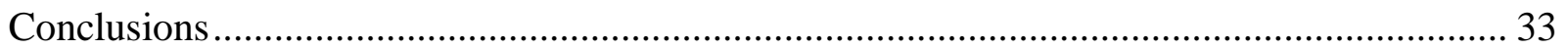

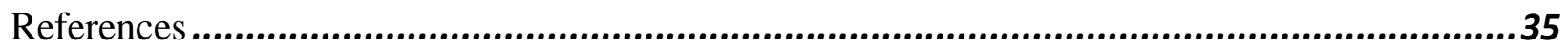




\section{Implementation of a Training Program to Improve the CRNA Precepting Experience at an Academic Medical Center}

Nearly 80 certified registered nurse anesthetists (CRNAs) employed at a major academic medical center in West Virginia serve as clinical preceptors for adult learners including student registered nurse anesthetists (SRNAs) and recently hired CRNAs. The facility's department of anesthesiology does not have formal preceptor training in place to optimally prepare CRNA preceptors for this role. CRNA preceptor training has been shown to improve the preceptors' confidence, comfort, and satisfaction with the precepting experience (Scott-Herring \& Singh, 2017a, 2017b). This DNP project proposed to implement formal CRNA preceptor training at this academic facility improve the CRNA preceptor and adult learner experience.

Training programs to become CRNAs are demanding, requiring at least 2000 hours of clinical practicum, at least 80 credit hours of didactic coursework over 3 continuous years, and development of a project to demonstrate scholarly learning. SRNAs apply didactic principles in the operating room (OR) and sharpen cognitive and psychomotor skills by administering hundreds of anesthetics to patients of all ages and levels of acuity, under the guidance of a clinical preceptor. Clinical preceptors, most commonly CRNAs and frequently anesthesiologists, guide the clinical learning of SRNAs. SRNAs are assigned to patients rather than the preceptor, so the SRNA's clinical learning is subject to various teaching styles and personalities of individual preceptors. Upon graduation from a training program, graduate nurse anesthetists must pass a national certification examination (NCE) to become certified, marking a transition to practice in which preceptors can support the new CRNA to ensure success, satisfaction, and retention (Tracy, 2017). 
Challenges to effective transitions in practice are not unique to new CRNAs. Sorrentino (2013) discussed how the clinical expertise of experienced nurses may regress to an advanced beginner level following a transition to a new work environment, which is a significant regression considering Benner's Novice to Expert model for the learning needs of onboarding CRNAs. Even experienced CRNAs are challenged with this phenomenon. Both types of CRNAs new to the facility, new graduates and experienced CRNAs, need purposeful and targeted clinical assignments, familiarity with the new working environment and equipment, and socialization among coworkers to acclimate to the professional, organizational, and social environment. CRNA preceptors in the department facilitate this process.

Preceptors fulfill a variety of important roles when working with adult learners, including leader, teacher, educator, coach, encourager, protector, record keeper, advocate, role model, socializer, evaluator, and mentor (Travis, 2020). A good preceptor possesses the skill set to determine the nature of the relationship to the adult learner, which may progress from teaching to coaching to mentoring. Teaching involves complete participation with the student or new employee, who may be mostly dependent on the preceptor to learn professional skills or organizational norms. Coaching is similar to teaching with respect to the involvement, only at a slightly lesser oversight. A preceptor coaching an adult learner may need to refine, rather than introduce, a learned skill or behavior. The preceptor-learner relationship may eventually evolve into a mentoring role in which the mentor provides occasional yet personalized and timely guidance when assistance is sought. CRNAs at this academic medical center are expected to fulfill all these roles. Formal preceptor training on how to effectively accomplish those roles may improve the precepting experience for the CRNA and the overall experience for the adult learner. 
Formal preceptor training improves consistency of the educational programming and the confidence and comfort of the preceptors in working with adult learners.

Clinical skills of the CRNA preceptor are important, but more important to the learning experience is the ability of the CRNA to effectively enable the adult learner to develop clinical skills in performance, critical thinking, problem-solving, and decision-making. A breakdown in the ability of the CRNA to convey those clinical skills negatively impacts the learning experience, which leads to undue stress for both the preceptor and adult learner. An effective clinical learning experience can help the learner to focus less on the dynamics of the precepting relationship and more on the care of the patient. According to Scott-Herring and Singh (2017a, 2017b), a formal training for CRNA preceptors can improve the overall confidence, comfort, and better prepare them for clinical precepting. A prepared and confidently trained CRNA preceptor will produce more competent CRNA clinicians.

\section{Available Knowledge}

A literature search was completed by utilizing the population, intervention, comparison, outcome, and time (PICOT) format to yield the most relevant evidence (Melnyk \& FineoutOverholt, 2019). The PICOT question used to guide the search for this project was, "In CRNA preceptors $(\mathrm{P})$, how does completing a formal training module (I) compared to not completing a training module $(\mathrm{C})$ affect the precepting experience $(\mathrm{O})$ while clinically precepting $(\mathrm{T})$ ?" With the focused PICOT question, applicable studies were found on this current practice inquiry which provided possible interventions for this perceived issue.

The project lead found literature to support this quality improvement (QI) project by doing a systematic search using databases and had also received relevant articles from stakeholders. PubMed, CINAHL, MEDLINE, and Academic Search Complete were the 
databases used to locate available literature. The American Association of Nurse Anesthetists (AANA) website was also used to find relevant information. Various search words were used to find the supporting studies and articles; they included: "certified registered nurse anesthetist," "preceptor," "training," "new graduates," "preceptor training program," “outcomes," “benefits,” “effects," “impact," “effectiveness," “new-hires," “new employees," “improve," “increase," “enhance," and "promote." Limitations placed within the search criteria on the database searches were "clinical trials," "2015-2020," and the "English language." This yielded a total of 2,257 hits with six being the most relevant studies that will be discussed in this literature review and synthesis. These studies were chosen due to evaluating the effectiveness of a formal training for preceptors and fulfilling the search criteria stated above. All hits with this search criteria were not reviewed due to the extensive amount. There were no further limitations were placed on this search in fear of missing relevant material.

The six most relevant studies found during the literature search were critically appraised for quality and significance. All studies had supporting data for various versions of preceptor training that improved preceptor effectiveness and experience.

\section{Literature Review}

Scott-Herring and Singh (2017b) utilized the pre-intervention-post-test design on a single group of CRNAs. The purpose of the QI project was to determine if the intervention would increase the satisfaction, confidence, and comfort of the CRNAs and better prepare the CRNAs for precepting. The intervention was a 4-hour CRNA preceptor workshop on one Saturday morning. The article reviewed the content covered during this workshop, which included: Council on Accreditation (COA) requirements, preceptor roles and responsibilities, self-efficacy, learning theory, assessing learners' needs and learning styles, conflict management and 
resolution, provision of constructive feedback, and current issues in SRNA education. The participants were on a self-selected (volunteer) basis, and they received four AANA Class A credits upon completion of the training. There was a total of 33 participants who completed the study. After the intervention was implemented, all three outcomes were found to be statistically significant for precepting SRNAs ( $\mathrm{p}<0.001)$ : satisfaction, confidence, and comfort. A weakness in this study was that the preceptors were self-selected to attend the intervention. Lack of randomization could affect internal and external validity.

In another study by Scott-Herring and Singh (2017a), they again used the preintervention-post survey design. This project evaluated whether the intervention improved satisfaction and comfort for precepting CRNAs and newly hired CRNAs. The intervention was an educational training session that focused on communication skills. During training, preceptors learned how to provide constructive feedback, and assess learning styles. This content was offered weekly for 3 weeks (three 1-hour sessions). The preceptors were also given a checklist to follow that included basic goals of orientation for onboarding CRNAs. There was a total of 12 preceptors and two orientees in this sample. A significant increase was found in satisfaction $(\mathrm{p}=0.002)$ and comfort $(\mathrm{p}=0.009)$ scores in the post-survey. Both onboarding CRNAs $(\mathrm{n}=2)$ voiced they were satisfied and confident upon completion of their orientation. There was a threat to external validity due to the small sample size and study design.

Easton et al. (2017) developed a QI project which included evaluating a training module, CRNA Preceptor Training Tutorial (CPiTT) for CRNAs to improve the precepting experience. This project included four phases: (1) developing the training, (2) presenting the content to CRNAs ( $\mathrm{n}=24)$ and SRNAs ( $\mathrm{n}=20)$ at a mentoring event to gain input, (3) baseline survey of current practices, (4) modification of the training depending on the survey results. According to 
Easton et al. (2017), the training modules included information on the following: the preceptor role; description of theory informing teaching; approaches to promoting student success; review of coaching, cueing, and prompting strategies; use of an "educational time out"; goal setting; constructive feedback and debriefing; effective evaluation; improving transfer of clinical and safety skills; and addressing challenging precepting situations. Surveys and face-to-face data were collected for the evaluations of the CPiTT training to make appropriate adjustments to the training for improvements; the data was immediately de-identified to protect the results. Ultimately, this project found that both CRNAs (62\%) and SRNAs (94\%) felt that formal training for preceptors created an effective precepting experience. Weaknesses noted within this project included a small sample size and participant inclusion (SRNAs and CRNAs) from only one nurse anesthesia program. Self-selection bias is also a threat to internal and external validity, because there was no randomization to obtain the sample. The authors did recommend that a longitudinal study be completed to truly evaluate the effectiveness of CPiTT on improving the teaching-learning environment, even though the overall response to the training was positive.

Shealy et al. (2019) conducted a study to evaluate self-perceptions and confidence of pharmacy faculty $(n=15)$ and preceptors $(n=30)$ by using a pre-intervention-post survey design. The intervention was a training program that incorporated an active-learning component. The authors discussed how preceptors are to evaluate and promote confidence and self-awareness in their students, which is a skill that preceptors often lack. The intervention was a 2-hour training session with a 1-hour active learning session, which allowed the participants to apply the learned material. A longitudinal follow-up survey was open for completion for 2-weeks following the training. The results were de-identified to minimize bias. The faculty members showed an improvement in self-confidence $(\mathrm{p}=0.002)$ on a 5-point Likert-based scale. Preceptors showed an 
increase of 0.6 points (on a 5-point Likert scale) in self-confidence for tailoring their precepting style to fit the learners needs. The faculty also felt this intervention improved student experiences $(\mathrm{p}=0.007)$.

Ryan et al. (2017) also utilized the pre-intervention-post survey design to evaluate whether an online learning resource is beneficial to nursing clinical preceptors. This study took place in Australia and included 15 participants. The intervention was a 4-hour workshop offered at two different locations at two different times. The Capabilities of the Nurse Educator (CONE) questionnaire was used in this study. The questionnaire has a Cronbach's alpha as $>0.9$ and high reliability. Participants reported they previously felt unprepared for the preceptorship role and had never had a formal training. Many of the evaluated items in the CONE assessment showed a statistically significant improvement between the pre- and post-surveys. Three items, confidence in teaching $(\mathrm{p}=0.012)$, self-confidence $(\mathrm{p}=0.028)$, and the ability to plan activities that improve learning ( $\mathrm{p}=0.001)$, were found to be relevant statistics for the current project. For this study, the sample was gathered via snowballing method to invite participants from two different hospitals, not by randomization; so, this could be a threat to internal and external validity. Also, results cannot be generalized due to the small sample size.

Elisha (2008) developed and implemented a training program for CRNA clinical educators. The 8-hour course included material about adult learning principles, conducting student evaluations, effective communication, creating positive relationships, and providing constructive feedback. Real-life dilemmas along with discussion were also incorporated to maximize active learning techniques. This study had 33 volunteer participants and used a preintervention-post survey design. There was an additional survey completed 2 months post intervention to measure retained material. Surveys included Likert scale items and open-ended 
questions. The questionnaires were tested for validity by using Cronbach alpha item analysis. Sixteen of the 22 items on the questionnaire indicated a statistically significant increase in perceived behaviors and knowledge toward clinical precepting. All eight open-ended questions, which were used to measure perceived knowledge of the CRNA clinical educators, indicated a statistically significant increase from pre-to post-course results.

\section{Literature Synthesis}

Six studies appraised for this project utilized the pretest-intervention-posttest design (Easton et al., 2017; Elisha, 2008; Ryan et al., 2017; Scott-Herring \& Singh, 2017a, 2017b; Shealy et al., 2019). The results of these studies supported the use of some form of training session to improve preceptor satisfaction and comfort (Easton et al., 2017; Elisha, 2008; Ryan et al., 2017; Scott-Herring \& Singh, 2017a, 2017b; Shealy et al., 2019). Four of the studies evaluated CRNA preceptors (Easton et al., 2017; Elisha, 2008; Scott-Herring \& Singh, 2017a, 2017b), one focused on pharmacy preceptors (Shealy et al., 2019), and the fifth looked at registered nurse (RN) clinical preceptors for enrolled nurses (Ryan et al., 2017). Five took place in the United States (Easton et al., 2017; Elisha, 2008; Scott-Herring \& Singh, 2017a, 2017b; Shealy et al., 2019) and one was done in Australia (Ryan et al., 2017). Two of the studies' interventions were online trainings (Easton et al., 2017; Ryan et al., 2017) and four incorporated in-person workshops (Elisha, 2008; Scott-Herring \& Singh, 2017a, 2017b; Shealy et al., 2019). Even though these studies differ slightly in how they were implemented and evaluated, they all show that having a formal training program can improve the overall precepting experience (Easton et al., 2017; Elisha, 2008; Ryan et al., 2017; Scott-Herring \& Singh, 2017a, 2017b; Shealy et al., 2019). Also, the participants were not all CRNAs, but again the concept of formal training to improve precepting training holds true across several different professional disciplines 
(Ryan et al., 2017; Shealy et al., 2019). This supports the current objective: offering the CRNAs at this medical center the opportunity to obtain a formal clinical preceptor training session to improve their precepting experience.

Although these studies varied slightly in their method and their teaching materials were not all identical, they were supportive of having a formal training to help assist in the preparation for precepting (Easton et al., 2017; Elisha, 2008; Ryan et al., 2017; Scott-Herring \& Singh, 2017a, 2017b; Shealy et al., 2019). Common educational topics in the literature for preceptor training sessions were adult learning principles, effective communication, providing effective feedback or evaluations (Easton et al., 2017; Elisha, 2008; Scott-Herring \& Singh, 2017a, 2017b; Shealy et al., 2019). These concepts are covered within the intervention for this project, Preceptor Essentials Parts I and II computer-based learning (CBL) modules on NetLearning (C. Travis, personal communication, September 4, 2020). Offering a formal training about these important concepts to the CRNAs, at the proposed implementation site, could improve their confidence, comfort, and satisfaction with precepting (Scott-Herring \& Singh, 2017a, 2017b).

\section{Rationale}

The theoretical framework referenced for this intervention is the Plan-Do-Study-Act (PDSA) cycle. The opportunity to cycle back to the beginning and refine the original plan for improvement is the reason this model was chosen. The CRNA participants were given the opportunity to provide feedback on the training material, in hopes to adjust the training material to improve the content and usefulness of the training for this group of preceptors. Also, according to Melnyk \& Fineout-Overholt (2019), this theoretical framework is utilized for QI projects to implement small-scale changes. 
In the "plan" stage of the cycle, observing the current process and identifying where improvements can be implemented is the primary goal. A literature search was completed for practice-based evidence to assist in developing an improved process for the CRNAs precepting adult learners, SRNAs and onboarding CRNAs, at the academic medical center. Completing the literature review revealed that implementing a formal training for CRNAs improved the confidence and comfort level toward precepting adult learners. The "do" stage consists of implementing a small-scale practice change (Melnyk \& Fineout-Overholt, 2019). During this stage, a presentation was given during a morning meeting of the anesthesia department to introduce the QI project. Then the CRNAs had self-selected to participate and were assigned the Preceptor Essentials modules on NetLearning. These modules were completed at their convenience. These modules served as the training or intervention of this project. A pre-training survey was completed by all self-selected participants after the meeting, but prior to taking the modules. The participants were given 1-month to complete the modules. Next, the post-training surveys represented the PDSA study stage. The final stage is "act." The PDSA act stage will be done by taking the survey results from the CRNAs' pre-post-training surveys and making appropriate revisions to the training plan for the precepting CRNAs. The PDSA model is effective for implementing a QI change at the department level. This framework allows small changes for a larger and more positive outcome- improving the CRNAs comfort, confidence, and satisfaction with precepting adult learners.

\section{Specific Aims}

The purpose of this project was to implement a formal preceptor training at a large academic medical center. The first aim was to improve the precepting experiences for the CRNA preceptor. Three outcomes assessed during the evaluation of the intervention were increased 
comfort, increased confidence, and increased satisfaction with preparation for precepting. These outcomes were intended to show evidence of improved preceptor experience while precepting adult learners, including SRNAs during their clinical rotation and CRNAs orienting to a new position.

The second aim of this project was to evaluate the usefulness of the Preceptor Essentials modules. Objectives for this aim included satisfaction with the CBL's self-paced, online learning content. Participants were asked on the post-training survey whether the training module needs to be modified to further improve the precepting experience for CRNAs at this medical center.

\section{Methods}

\section{Context}

This project was implemented within the anesthesia department at a 674 bed, level-I trauma academic medical center in WV. The main hospital opened a new heart and vascular tower in the past 3 years and is building a pediatric tower scheduled to open in 2022, which will double the size of the medical center from what it was just a decade ago. The health system has a close relationship with its neighboring major university, providing clinical training to students in many professional programs in medicine, nursing, and the allied health sciences. High patient acuity at this center, combined with its nature as a regional referral center for the most complex surgical cases, contributes to the intensity and responsibility of learners and their preceptors to deliver appropriate care.

The department of anesthesiology employs over 50 anesthesiologists and nearly 80 CRNAs who work collegially in a team model. The anesthesiologists are present to assist with induction, when the patient is going to sleep at the beginning of the case. The CRNAs maintain the anesthetics, consult with the anesthesiologist if needed during anesthesia delivery, and notify 
them at the end of the case to be present to awaken the patient. The anesthesiologists are available for consultation, but the CRNAs are the primary hands-on anesthesia providers for the medical center's nearly 40,000 anesthetic cases (A. Ostrowski, personal communication, September 16, 2020).

The growth of the medical center increased the demand for hiring new and experienced adult learners, so the department expanded proportionally in size. Approximately 20 anesthesiologists and 45 new and experienced CRNAs were added to the department over 3 years. The department provides clinical education annually for 10 residents in anesthesiology and accommodates 7 or 8 SRNAs per month from 3 nurse anesthesia programs in the region. The university's school of nursing was accredited in November 2019 to train 15 SRNAs per year, and they joined the department as a new group of trainees in November 2020. The department's CRNAs are the primary preceptors for all SRNAs who rotate to this clinical site for training. Many of the CRNAs have been occasional preceptors for new CRNA employees and SRNAs for many years. However, regular hiring of new employees and a new training program adding future cohorts, will require more CRNAs to regularly work with adult learners (A. Ostrowski, personal communication, September 16, 2020). With this increased demand on these preceptors, having a formal preceptorship training was intended to minimize the pressure and increase comfort and confidence with this task.

\section{Evidence of Key Site Support}

The anesthesia department chair and chief CRNA had given their full support for implementation of this project. The chief CRNA also served as a consultant for this project within the department at the site of implementation, connecting the project leader to the department. 


\section{Intervention}

An introductory presentation was given by the project leader and the Faculty of Record (FOR) during a regular departmental meeting to introduce the project on February $10^{\text {th }}, 2021$. Basic information was presented describing the proposed project for the CRNA preceptors, including the timeline for the project, proposed intervention, and projected outcomes. The participants were self-selected following this presentation. They were identified via a sign-up sheet in the auditorium and a mass message from the chief CRNA to the staff in case they had decided to participate after the day of the presentation, or they did not have the opportunity to place their name on the sign-up sheet. Once the participants were identified, they were provided a link to the pre-training survey via email. This link directed them to the online pre-training survey on Qualtrics, survey software by Experience Management (2020).

The intervention was a series of two CBL modules, Preceptor Essentials Parts I and II, delivered on the hospital's CBL platform (NetLearning). This intervention consisted of an online portion of a training series which usually includes an in-person workshop following the training modules. The training series was modified to include only the online training due to the Coronavirus pandemic restrictions, which no longer permitted in-person workshops to take place. The in-person workshop was a basic review and discussion of the material within the training modules (C. Travis, 2020). The modules took approximately 2 hours to complete. Participants were able to complete the modules at their own pace within the requested timeframe of 1 month. The Preceptor Essentials Parts I and II include material on preceptor roles and tools, adult learning styles, competency verification, phases of acclimation, generational diversities with learning, communication styles, and feedback methods. 
The Preceptor Essentials modules were designed as formal training for the medical center's precepting nurses. The NetLearning platform is a website utilized for employee onboarding, mandatory annual competencies, and voluntary continuing education for hospital employees (C. Travis, personal communication, September 16, 2020). CRNAs at this medical center use NetLearning to complete annual mandatory training, and content from Preceptor Essentials I and II translates well to the precepting needs of the CRNA. These training modules can be added to the list of CBLs for the CRNAs to complete during onboarding or orientation.

The project leader proposed to evaluate whether formal preceptor training would improve the CRNA's knowledge, comfort, and confidence with precepting adult learners. Participants for this project were self-selected CRNAs who had precepted or were interested in precepting adult learners in the medical center's department of anesthesiology. Participants understood they were able to withdraw at any time during the implementation and evaluation of the intervention.

The project was implemented following a pre-training - intervention - post-trainingsurvey design. CRNA participants answered pre-training questions related to comfort, confidence, and satisfaction with precepting preparation through electronically administered Likert scale surveys. Participant retention of the module content was assessed by a quiz at the end of the NetLearning modules. Participants then completed a post-training survey after the preceptor training modules to again assess CRNAs' comfort, confidence, and satisfaction with precepting preparation. The post-training survey also evaluated the usefulness of the modules for CRNA preceptors. The questions evaluated the participant's satisfaction with the modules' material and method of online, self-paced education. Topics covered in the Preceptor Essentials modules aligned with topics recommended in the review of the literature, such as adult learning 
principles, effective communication, providing effective feedback and evaluations (Easton et al., 2017; Elisha, 2008; Scott-Herring \& Singh, 2017a, 2017b; Shealy et al., 2019).

\section{Benchmarks and gaps in evidence}

The Preceptor Essentials modules on NetLearning are currently a part of the nursing preceptor training in the medical center and provide a benchmark of quality for this project. The module is endorsed by the medical center's nursing education department. The content of the modules was vetted by CRNA nursing educators for validity, translates well to the learning needs of the CRNA preceptor, and addresses topics found in the literature (Easton et al., 2017; Elisha, 2008; Ryan et al., 2017; Scott-Herring \& Singh, 2017a, 2017b; Shealy et al., 2019). One gap identified in the literature addressed by this project is the usefulness of an online preceptor training program to improve the preceptor experience for the preceptor and adult learner.

Organization's strategic plan. The mission statement of the academic medical facility is "to improve the health of West Virginians and all we serve through excellence in patient care, research, and education" (WVU Medicine, n.d.). To meet these goals, the facility must strive for excellence to educate and precept West Virginians to practice as nurse anesthetists. Precepting requires the CRNA to pass expert knowledge to SRNAs during clinical rotations and onboarding CRNAs during orientation. An effective preceptor will serve as a role-model, both in and out of the OR by guiding decisions, challenging thoughts, and advancing critical thinking skills. Having a CRNA feeling comfortable and confident with precepting can lead to an improved precepting experience for the precepting CRNAs and the adult learning preceptees. A current CRNA employee at the academic medical center revealed there is no formal training for precepting CRNAs at this facility (K. Meyers, personal communication, June 22, 2020). Providing formal CRNA preceptor training can offer clinical precepting guidance, which may improve CRNAs' 
comfort and confidence with the task of precepting. According to Scott-Herring and Singh (2017a, 2017b), providing training sessions for preceptors significantly increased their satisfaction and comfort with precepting.

The project team was led by a student, who distributed the surveys and served as the main point of contact for any participant questions during the training phase. The FOR advised the project leader, monitored progress, and assisted in brainstorming any issues faced by the project leader. The chief CRNA, the consultant, was the main point of contact and the link to the department for the project leader. The consultant facilitated the introductory presentation during a weekly CRNA staff meeting and promoted the training to the department's CRNA staff. The self-selected CRNA participants completed the pre-post-training surveys and the modules on their own time, either at the hospital or their home. After all participant surveys were completed, results were analyzed with a statistician.

Technical equipment utilized for this project included computers with various software applications, including NetLearning and Qualtrics. NetLearning is a preexisting training platform accessible in the hospital or remotely by all CRNAs and Qualtrics, surveying software licensed by West Virginia University, was used to develop and administer all surveys associated with this project.

Budget. The budget for this project was minimal, see Appendix A. The project leader volunteered the time needed to implement the project. The intervention, the modules on NetLearning, are free for hospital employees. The self-selected CRNAs spent their own time completing this module and the introductory presentation was completed during a regular employee meeting, so no additional pay to employees was needed. The participants could apply to obtain continuing education (CE) credits, which are required for renewing their RN and 
CRNA certifications. The return on investment is difficult to quantify, but along with obtaining the two CE credits, they will have also improved their precepting preparation and experience.

\section{Evaluation Plan}

The approach chosen to assess the impact of the intervention followed the Simple Logic Model, see Appendix B (Zaccagnini \& White, 2017). Inputs included the volunteered time from the project leader and the participants; and comfort and confidence of the CRNA volunteers with precepting adult learners prior to the intervention. Comfort and confidence were assessed by using the pre-training survey. Outputs included the Preceptor Essentials Parts I and II modules on NetLearning, which are designed to prepare the CRNAs for precepting. Outcomes were assessed by using the post-training survey.

The modules on NetLearning were the only variable manipulated between the pre- and post-training surveys. Unforeseen factors may have contributed to the outcome, but this is one way to minimize that risk.

\section{Measurable Aims}

Primary Aim. Improve the preceptorship experience for CRNAs.

First Objective. The project lead gave an introductory presentation to the CRNAs during a monthly staff meeting. Following the presentation, self-selected CRNAs were recruited to participate in the QI project.

Second Objective. The project leader facilitated the CRNA volunteers to complete the Preceptor Essentials Parts I and II modules on NetLearning by sending instructions on how to enroll and complete the training. Successful completion was measured by collecting a NetLearning certificate from the participants. The project was feasible because participants were given 1 month to complete the modules during downtime at work or remotely at home. 
Third Objective. The project lead enabled the completion of the post-training surveys, measured by quantitative analysis of Likert surveys administered via Qualtrics survey software. The participants received an email with the survey link. Participants rated their satisfaction with precepting preparation and comfort and confidence with precepting on a 5-point scale from "not at all" to "very much." The post-training survey included the same questions and format as the pre-training survey, except for the additional binary and open-ended questions to evaluate the usefulness of the intervention and any suggestions for improving the training material.

Data were planned for collection and analyzed in consultation with Dr. Kesheng Wang, the WVU School of Nursing's statistician. Dr. Wang recommended the Mann-Whitney U (rank test) with IBM's SPSS Statistical Software. The statistical test was intended to help the project leader evaluate the effectiveness of the modules on improving the perceptions and attitudes of the CRNAs in precepting adult learners, including SRNAs and onboarding CRNAs. All data gathered from the participants were deidentified and identities were kept separate from the data results.

Second Aim. Evaluate the usefulness of the Preceptor Essentials modules on NetLearning.

First Objective. An objective towards achieving this aim was the completion of the posttraining survey by the participants. Likert-type and open-ended questions were intended to evaluate two outcomes. The first outcome measured the CRNAs' satisfaction with the modules learning content. The second outcome measured the satisfaction with the CBL mode of learning, computer based and self-paced. The Likert-type questions had 5-level ratings, from "not at all" to "very much." This data had been collected by utilizing the Qualtrics application and analyzed by 
using SPSS Statistical Software. Details of this evaluation plan are summarized in a chart in Appendix C.

\section{Measures}

The specific survey questions the project lead chose to evaluate the outcomes of this QI project were adapted from surveys used in similar studies. Approval to use these surveys was obtained from both the author of the articles reviewed for this project and the creator of the surveys (M. Scott-Herring, personal communication, July 21, 2020; K. Sandau, personal communication, October 2, 2020). According to Scott-Herring and Singh (2017a, 2017b), the surveys had been tested for internal reliability by utilizing the Cronbach alpha coefficients test, which was 0.82 for these surveys. The validity has also been established by a group of three experts, one of which included K. Sandau, $\mathrm{PhD}, \mathrm{RN}, \mathrm{CNE}$, the creator of the surveys (ScottHerring and Singh, 2017a, 2017b).

Contextual elements that contributed to the success of the project participation was the location of implementation, a large academic medical center, which has a motivating environment for continual staff improvements. A factor that could have skewed the outcome data was the additional precepting experience the CRNAs had done between completing the pre- and post-training surveys. Having that recent additional experience could have increased the comfort and confidence of the precepting CRNAs and not the intervention of the modules. This will be taken into consideration when evaluating the data. Partially completed data was excluded, only fully completed surveys were accepted for evaluation. Also, only the participants that had completed the modules were given the opportunity to complete the post-training survey. Lastly, the pre-training survey evaluated whether the CRNAs had received preceptor training in the past, this was also taken into consideration when collecting and evaluating the available data. 
The cost of this project was minimal, as planned. The potential need for paper surveys was the only anticipated cost and this was a backup plan should the participants not have the means of completing the pre- and post-training surveys via Qualtrics Survey Software. This was never an issue throughout implementation, so the QI project did not require any monetary investment. Also, the modules' training platform was NetLearning, which is already utilized by the hospital employees, so this route for implementing the training was cost-efficient.

A statistically significant improvement in CRNAs' attitudes and perceptions on precepting and satisfaction with the Preceptor Essentials Parts I and II modules, could set a new standard for CRNAs at this facility, formal preceptor training before fulfilling the CRNA clinical preceptor role. If the Preceptor Essentials Parts I and II modules are found to be an effective training tool, they could become part of the NetLearning training requirements for the CRNA preceptors within the department. The new requirement would sustain the implementation and promote that all CRNAs are trained and equipped to maximize the success of precepting adult learners, including SRNAs and onboarding CRNAs within the facility of interest.

\section{Analysis}

One method used to draw inferences from the data was comparing the pre-training survey results to the post-training survey results. The pre-and post-training surveys included the same questions for ease of comparison. Quantitative data was entered into SPSS Statistical Software and the average (mean rank) of the Likert-type survey questions from the pre-training survey was compared to the post-training survey average of the same question. The qualitative data came from open-ended questions for an opportunity to provide feedback about the topics covered within the training. 
Two variables could affect variation in the data: increased precepting opportunities during the training interval and previous preceptor training. Variation in the data could be due to individual CRNA volunteers having the opportunity to precept more SRNAs or onboarding CRNAs in the timeframe between the two surveys. This type of variation was attempted to be managed by minimizing the time between the pre- and post-training surveys. This variable, the amount of precepting experiences by the CRNA volunteers, could not be controlled due to continuous presence of SRNAs and frequent hiring of CRNAs at this facility. Another factor that could have accounted for variations in the results was if the CRNA participant had previous preceptor training, this was assessed in the pre-training survey.

\section{Ethical Considerations}

The project proposal was screened and approved by the Institutional Review Board. There were no foreseen specific ethical issues that needed addressed prior to implementation. Autonomy of the participants was preserved because they had volunteered to take the preceptor training and were aware of the opportunity to withdraw at any time during the intervention. None of the participants were intended to be at risk for harm in the implementation of this project. There were no repercussions for not participating or withdrawing from the project. To the contrary, participants could earn two CE credits for completing the modules. No identifying information, other than age, was obtained from any participant, nor were patients under the care of the volunteer CRNAs in any way involved directly or indirectly with this project. The data collected from the participants were kept separate from their identifying information.

At the time of implementation, the project leader was an SRNA, creating a possible conflict of interest. There is the potential that improving the precepting experience for the 
CRNAs and SRNAs was a motivator for the project. Another possible conflict of interest would have been including other students in the implementation or data collection.

\section{Results}

The initial step of the project was an informational presentation to the anesthesia department on February 10, 2021. This meeting served as the venue to maximize the number of precepting CRNAs present at one time from the department. The presentation included pertinent information such as the identified problem, literature summary, timeline, and participation requirements. Once the presentation was complete, the CRNAs interested in participating either placed their name on the sign-up sheet or emailed the project leader their contact information. A total of 29 CRNAs expressed interest in participating in this QI project.

The intervention began by sending the participants a Qualtrics Survey Software link to the pre-training survey. This link was disseminated to the participants on March $1^{\text {st, }}$ and they were given until March $15^{\text {th }}$ to complete. Of the 29 original invitations, 19 pre-training surveys were completed and these CRNAs were given the information to complete the Preceptor Essentials Parts I and II modules.

Next, the project leader designed instructions on how to enroll in the proper course on NetLearning. These step-by-step instructions were emailed to the participants to minimize any confusion on which training to complete or any complications with locating the training. The Preceptor Essentials Parts I and II modules were completed by the April $30^{\text {th }}$ deadline. Eleven participants completed both Preceptor Essentials Modules.

The post-training survey was then completed by July $31^{\text {st }}$. This deadline was extended from April due to keeping the surveys anonymous and having Qualtrics Survey Software complications. Post-survey links were sent to all participants at the same time to keep the survey 
results anonymous and minimize the project leader's ability to link survey times of submission to specific participants. The post-training surveys were sent out for completion on May $1^{\text {st }}$, with the intent of having all completed by May $15^{\text {th }}$. By the first deadline, there had been zero surveys completed. A reminder email was sent, and the deadline goal was extended two more weeks. The project leader was informed by one of the participants that the survey link had expired. The Qualtrics Survey Software link expiration date was extended, and this fixed the issue. The participants were informed of this unexpected delay and the deadline was extended to July $31^{\text {st }}$ to ensure all participants were given the opportunity to complete the post-training survey. See Appendix D for project implementation timeline.

The process measures were analyzed with surveys which included Likert-type questions and open-ended questions for specific feedback from the participants. The pre-training surveys (Appendix E) and post-training surveys (Appendix F) were adapted from a similar previous study with permission from the author of the articles reviewed and the creator of the surveys. A 5-point scale from "not at all" to "very much" were ratings for questions that assessed the satisfaction with preceptor training, confidence and comfort in the ability to precept adult learners, comfort in working with adult learners who have a different personality or learning style than their own, and confidence in providing positive and negative constructive feedback to adult learners. The results to these surveys were entered into SPSS and the Mann-Whitney U test was used to analyze the significance of the data results. This test evaluates the ranking of data by comparing the mean value of the ranks between the pre- and post-training survey results. See Appendix $\mathrm{G}$ for the mean rank and statistical test tables.

The first survey question evaluated whether the participants were satisfied with their preparation for precepting. There was a statistically significant $(\mathrm{p} \leq 0.05)$ increase with the 
satisfaction of precepting preparation $(\mathrm{p}=0.029)$ based on the formal training offered. The mean rank increased from a mean of 13.03 to 19.77 from the pre- to post-training surveys.

The preceptors' confidence in their ability to precept adult learners $(p=0.629)$ and comfort in actively coaching critical thinking adult learners $(\mathrm{p}=0.337)$ did not increase to a statistically significant difference. The mean in confidence raised from 14.95 to 16.45 between the pre- and post-training surveys and the mean in comfort in actively coaching adult learners improved to a mean of 17.32 from 14.45 . These results do show improvements, but they are not statistically significant. Also, the comfort in working with adult learners with a different personality or learning style from their own did show improvement in the mean rank (14.76 to 16.77), but again, these results were not statistically significant $(\mathrm{p}=0.507)$.

The confidence in the preceptors' ability to provide both positive and negative constructive feedback to adult learners improved from a mean rank of 13.37 to 19.18 , which showed a borderline significant difference $(\mathrm{p}=0.067)$. Having the ability to provide constructive feedback to SRNAs and onboarding CRNAs is an important task for preceptors. It is essential to having an effective and productive learning environment and producing clinically competent practitioners.

The pre-training survey had a question which evaluated whether the participants had previous formal preceptor training. All CRNA participants denied ever receiving training prior to participating in this QI project. This was important to identify for minimizing other variables that could potentially skew the data.

The majority of the CRNA participants have been precepting adult learners for 6-10 years $(n=5)$ and 11-15 years $(n=5)$. Three CRNAs claimed to precept for 0-5 years, three for 16-20 years, and another three over 20 years. This exemplifies the vast experience these CRNAs have 
with precepting, and yet not one had ever received formal training on how to effectively perform this task.

One question was designated to gather the demographics of the participants. This question placed them in an age bracket. Ten of the participants were from 30-39 years old, six were 40-49 years old, and three were 50-59 years old. There were zero $(n=0)$ participants younger than 30 years old or older than 59 years old. This just gave a general idea of the sample of CRNAs that had completed the pre-training survey.

There were three final questions on the post-training survey that inquired about improving the preceptor training. One open-ended question asked what topics would be helpful in assisting to precept adult learners, there was no feedback received from the 11 participants. Also, a binary question (yes/no) inquired about the satisfaction with the mode of learning of this formal training. This training was computer based and self-paced, all the participants stated they were satisfied with the training. Lastly, an open-ended question asked for two things that they did like and did not like about the training, there was no feedback given from all 11 participants.

There are a few identifiable contextual elements that could have interacted with the interventions of this project. Not all CRNAs attended the regular employee meeting, so there could have been missed opportunity of having more participants because some were not made aware of the pertinent information about the project. This variable was minimized by distributing a mass email to all CRNAs about the project from the chief CRNA, but again, this was abbreviated information, so possibly not as effective as an in-person presentation.

Another contextual element that potentially interacted with the intervention is some CRNAs could have had the intent to complete the Preceptor Essentials Parts I and II modules, 
but simply ran out of time to complete them. COVID-19 had affected the work environment within the hospital, which may have created less downtime at work to complete both modules.

A contextual element that could be associated with the interventions and outcomes of the project is the site of implementation, at a large academic medical center. This type of environment is supportive of learning and advancing education, which could have motivated the CRNAs to participate in the project and complete the intervention. Also, since this is a teaching facility, there is a significant amount of precepting experience for the CRNAs, which could have affected the outcomes from having some comfort and confidence with performing this task already.

There were a few potential issues recognized with the process of the intervention. The emails with the Qualtrics pre- and post-training survey links were from triggers@qualtricsresearch.com, which could have caused some of the surveys to go to the participants spam mailbox or be unintentionally ignored or deleted. It would have been beneficial to come from the project leader, for ease of identifying the email with the Qualtrics link. Three participants had reached out to the project leader looking for the email. So, if this was not an issue, there could have potentially been a larger sample size for the project.

One unexpected issue identified was with the pre- and post-training surveys within the Qualtrics software program. If the two surveys had been linked or paired by an assigned identifier, the paired t-test could have been used instead of the Mann-Whitney U test. Using the paired t-test would have resulted in stronger quantitative data with the smaller sample size. With stronger results, there could have been more outcomes with statistically significant differences, such as increased comfort and confidence of preceptors. So, having the continuous outcomes would have been beneficial to clearly represent the impact of the intervention. Once the pre- 
training surveys had been distributed, they could no longer be linked because of not having an assigned identifier.

Another problem with the intervention affected the timeline of the project. This issue was with the expiration date of the surveys within the Qualtrics survey software. The survey links expired before the end of the data collection time, and this deactivation was unknown to the project leader. Once a participant informed the project leader of this, the expiration date was extended in the survey settings. Recognizing there was an issue, then troubleshooting and redistributing the post-training surveys delayed the completion of data collection by approximately 2 months. This could have affected the results of the survey due to the participants simply forgetting the specifics of the topics in the training. There was no qualitative feedback collected from the participants on the training material.

\section{Discussion}

\section{Summary}

Nurse anesthesia school is a mentally, emotionally, and physically demanding educational program; both clinically and didactically. Obtaining a nurse anesthesia degree is now at the doctoral level of education. The success of SRNAs in this type of program greatly relies on a good clinical experience and this starts with having a confident and prepared clinical preceptor. Onboarding CRNAs, whether bringing experience from another medical system or area of the hospital, are considered to be regressed from Benner's expert to advanced beginner level due to being in a new clinical setting (Sorrentino, 2012). These CRNAs need to gain solid experience in this new environment before becoming an expert again; this process begins with a comfortable and confident CRNA preceptor. Studies have shown that formal preceptor training improves the 
preceptor's comfort and confidence with precepting, not only with nurse anesthesia, but with other disciplines as well.

At the facility of interest, there is currently no formal preceptor training in place for the CRNAs to be optimally prepared for the important role of precepting adult learners. Completing the Preceptor Essentials Parts I and II on NetLearning showed a statistically significant increase in the satisfaction of the preceptors' preparation with precepting. The mean rank results for the post-training survey did show an increase in comfort and confidence with precepting, but the results were not statistically significant. Although the results were not statistically significant, the clinical significance of the results should not be dismissed. Also, there was an increase in the mean rank in the comfort of working with adult learners with a different personality or learning style than their own, but again this difference was not statistically significant. Lastly, the confidence in providing both positive and constructive feedback to adult learners had increased to a near statistically significant difference. Providing both positive and negative feedback to a preceptee is paramount to an effective learning clinical experience. Having all the mean ranks increase, even if not enough for showing statistical significance, supports there can be an improvement in the precepting experience with a formal preceptorship training, which is the first aim of this project. The second aim was to evaluate the usefulness of the Preceptor Essentials Parts I and II modules, the content within the modules and the mode at which it was offered, online and self-paced. The CRNA participants reported satisfaction with the intervention and its effectiveness.

The strengths of this project include essentially no monetary cost and obtaining two CE credits from NetLearning. Having CEs for renewal of licensure and certification is helpful to the participants. Also, improving the satisfaction in their preparation for precepting is another 
positive outcome of the intervention. Having formal training can promote teamwork and effective communication amongst preceptors and preceptees, creating a more positive clinical learning experience. Lastly, the NetLearning platform, is the platform utilized at the hospital of interest for other required trainings. So, the familiarity with navigating the interventional training was also a strength of the project.

\section{Interpretation}

The results of the post-training survey from the CRNA participants, when compared to the pre-training survey, all trended toward a higher ranking of increased level of preparation, comfort, and confidence with precepting, supporting clinical significance. The CRNAs' general feelings about precepting were most likely not due to the additional time they had to precept, but associated with the intervention, Preceptor Essentials Parts I and II. According to the pretraining survey, these CRNAs had been precepting for many years. So, the likelihood of the general increase in these feelings about precepting being a result of performing the preceptor duties in-between taking the pre- and post-training surveys is unlikely, although it cannot be completely ruled out.

The six studies appraised for this project supported the use of some form of training to improve preceptor satisfaction and comfort with precepting (Easton et al., 2017; Elisha, 2008; Ryan et al., 2017; Scott-Herring \& Singh, 2017a, 2017b; Shealy et al., 2019). The results of this QI project were not all statistically significant, although there was an improvement from the preand post-training surveys in all concepts evaluated, which does align with the findings from other publications. Not all studies reviewed had CRNAs as their participants (Easton et al., 2017; Elisha, 2008; Scott-Herring \& Singh, 2017a, 2017b). One study looked at RN clinical preceptors for enrolled nurses (Ryan et al., 2017), and another included pharmacy preceptors (Shealy et al., 
2019). The outcomes of these studies support the concept of utilizing formal training to improve the precepting experience across a variety of professional disciplines.

Scott-Herring and Singh $(2017 b)$ had shown a statistically significant $(\mathrm{p}<0.001)$ improvement in satisfaction, confidence, and comfort with precepting. In another study by ScottHerring and Singh (2017a), they had also found an increase in satisfaction and comfort between their pre- and post-surveys. Easton et al. (2017) used a CRNA Preceptor Training Tutorial (CPiTT) for CRNAs to improve the precepting experience. This project found that both preceptors (64\%) and the preceptees (94\%) felt that formal training for preceptors created an effective precepting experience. Shealy et al. (2019) conducted a study with pharmacy faculty, and they found their training program to improve self-confidence $(\mathrm{p}=0.002)$ within the faculty members. Ryan et al. (2017) found three items, confidence in teaching, self-confidence, and the ability to plan activities that improve learning to improve with the 4-hour workshop. Lastly, Elisha (2008) had developed a course that improved the perceived behaviors and knowledge towards clinical precepting with CRNA clinical educators. Again, although the current QI project did not show a statistically significant improvement in their comfort and confidence with precepting, as in the other studies, the mean ranks did improve from the pre- to post-training surveys overall. Also, there was a statistically significant difference in the satisfaction of their preparation for precepting, lending to the concept that improved preparation for a task should lead to improved outcomes.

The ability of the experienced and knowledgeable CRNA to effectively enable the adult learner to develop their critical thinking, problem-solving, and decision making will improve their overall clinical performance. Being clinically competent, will then have improved patient outcomes, which will lead to a positive experience for the patient. Having these positive 
outcomes and experiences supports the facility of interest's mission statement "to improve the health of West Virginians and all we serve through excellence in patient care, research, and education" (WVU Medicine, n.d.).

This project was anticipated to find statistically significant improvements in all variables reviewed: satisfaction with precepting, confidence with precepting, comfort level with actively coaching critical thinking adult learners, and confidence in providing both positive and constructive feedback to adult learners. Although there was an improvement, the comfort and confidence were not statistically significant. One reason for this was speculated to be the way in which the data was collected and not having the ability to link the pre-training survey to the corresponding post-training survey. Having the ability to compare the two results from a single participant, instead of the mean from the entire group, would have strengthened the data and potentially showed a statistical significance. Another reason for the difference between the expected and actual outcomes in comfort and confidence is based on the context in which the project was implemented, at an academic medical center. The CRNAs at this facility have been precepting for many years, owing to some comfort and confidence with the precepting task already.

The cost for this project implementation was minimal. The project leader volunteered the time needed for implementation and the CRNAs participated at their own leisure, either at work during free time or at home. Completing this training at work could lead to productivity tradeoffs within the hours they had spent at work completing this training instead of doing other improvements to the unit or providing anesthesia for surgical procedures. This was not a cost included in the original budget plan. There were no other hidden costs noted throughout the implementation process. 


\section{Limitations}

This project had a small sample size that completed both surveys and the intervention $(n=11)$. This small sample size limits the generalizability of the results. Another limitation to the generalizability is the context in which it was implemented, in an academic medical center. Again, the CRNAs at this facility do have a great amount of experience with precepting adult learners, this opportunity may not hold true across all medical facilities, affecting the perception with precepting. To generalize results across a population, a large, randomized study within a variety of facilities, would need completed, but this was not the intent of this QI project.

The CRNA participants within this project were not randomly selected, they volunteered following an introductory presentation. Volunteering can lead to a self-selection bias which could have been a threat to the internal and external validity of the project. Another notable limitation is the possibility of the additional time spent precepting in the timeframe between the pre-and post-training surveys, owing to the improvement of the outcomes, and not the intervention itself. The additional experience could be a potential confounding variable, but it is unlikely due to the vast amount of experience with precepting that most participants had leading up to this project implementation.

Another threat to internal validity was an imperfection in the method discovered during data collection. There may have been two participants that had answered the survey more than once. There were 19 pre-training surveys completed, but only 17 participants $(n=17)$ at that time. The survey link emailed to the participants did not lock out once it was completed. This notable imprecision in the method could have been avoided if this was a foreseen issue and settings on the Qualtrics Survey Software could have been modified. 
Lastly, there were some limitations with the results of the project. The analysis of the quantitative data would have been stronger using the paired t-test due to the small sample size. To do the paired t-test, the participants would have needed an identifier to link the pre-and posttraining surveys. The surveys were de-identified to minimize bias in answering the survey questions. Linking the surveys would allow the comparison of each pre-training survey to the post-training survey individually and not the mean value between the two groups. This was discovered with the statistician during a collaboration meeting. Attempts were made to link the data and Qualtrics Survey Software personnel confirmed there was no way to link the data once the data has been collected. Also, the post-training surveys lacked qualitative data responses. Receiving qualitative data from the participants would have provided feedback on ways to improve the training for the future.

\section{Conclusions}

Formal preceptor training has been shown to improve the preceptor experience across many different disciplines, including CRNAs (Easton et al., 2017; Elisha, 2008; Ryan et al., 2017; Scott-Herring \& Singh, 2017a, 2017b; Shealy et al., 2019). Preceptorship training may be delivered via in-person (Elisha, 2008; Scott-Herring \& Singh, 2017a, 2017b; Shealy et al., 2019), or online using a computer-based training method (Easton et al., 2017; Ryan et al., 2017), both have shown positive outcomes for the preceptors' comfort and confidence with precepting.

The current project was completed at a large academic medical center in West Virginia. The intervention was the Preceptor Essentials Parts I and II on NetLearning. NetLearning is an online platform currently used by the hospital employees for job specific training, making the sustainability of this project feasible. All the participants $(n=11)$ that completed this project had stated their satisfaction with the mode of learning, computer based and self-paced. They also did 
not list any additional topics that should be added or taken out to improve the training for their needs. This supported the usefulness of the training for the precepting CRNAs at this facility. Given the positive outcomes and the usefulness of the training, this training should become a requirement to all precepting CRNAs at the facility. This new standard would sustain the implementation and ensure that all CRNAs are trained and equipped to maximize the success of precepting adult learners, SRNAs and onboarding CRNAs, within the academic medical center which has a large focus upon teaching and advancing education for West Virginians.

While we anecdotally, based on the overall results, show improved comfort and confidence, these results could be evidence to replicate this topic in a more expanded fashion. Having a larger sample and addressing the limitations would result in stronger conclusions and sound recommendations across more settings.

The intervention for this project, Preceptor Essentials Parts I and II, are located on the NetLearning platform. This platform is not utilized at all medical facilities, making it difficult and ineffective to recommend using this intervention across other settings. Also, the sample was not randomized, so the outcomes and recommendations are not generalizable across all populations. It is recommended, however, that all preceptors be offered some formal preceptor training to improve comfort and confidence with the precepting task. Regardless of the profession, formal training will improve their experiences and outcomes. 


\section{References}

American Association of Colleges of Nursing. (2006, October). The essentials of doctoral education for advanced nursing practice. https://www.aacnnursing.org/Portals/42/ Publications/DNPEssentials.pdf

American Association of Nurse Anesthetists. (2019). Clinical preceptor guidelines. AANA Learn Online Continuing Education. https://shop.aana.com/all-courses/clinical-preceptorguidelineshtml

Bonnel, W. \& Smith, K. V. (2017). Proposal writing for nursing capstones and clinical projects ( $2^{\text {nd }}$ ed.). Springer Publishing Company.

Cupp Curley, A. L. (Ed.). (2020). Population-Based Nursing (3rd ed.). Springer Publishing Company.

Easton, A., O'Donnell, J. M., Morrison, S., \& Lutz, C. (2017). Development of an online, evidence-based CRNA preceptor training tutorial (CPiTT): A quality improvement project. AANA Journal, 85(5), 331-339. https://www.aana.com/aanajournalonline

Elisha, S. (2008). An educational curriculum used to improve the knowledge and the perceptions of certified registered nurse anesthetist clinical educators. AANA Journal, 76(4), 287292. https://www.aana.com/aanajournal.aspx

Knapp, H. (2017). Practical statistics for nursing using SPSS. SAGE Publications.

Melnyk, B. M., \& Fineout-Overholt, E. (2019). Evidence-based practice in nursing and healthcare (4th ed.). Wolters Kluwer.

Qualtrics Experience Management (2020). Qualtrics XM. https://www.qualtrics.com/

Ryan, C., Young, L., \& McAllister, M. (2017). The impact of an online learning platform about nursing education on enrolled nurse preceptor teaching capabilities: A pre-post-test 
evaluation. Contemporary Nurse, 53(3), 335-347. https://doi.org/10.1080/10376178. 2017.1347512

Sandau, K.E., Cheng, L.G., Pan, Z., Gaillard, P.R. \& Hammer, L. (2011). Effect of a preceptor education workshop: Part 1. Quantitative results of a hospital-wide study. The Journal of Continuing Education in Nursing, 42(3), 117-126.

Schooley, S. (2019, June 23). SWOT analysis: What it is and when to use it. Business News Daily. https://www.businessnewsdaily.com/4245-swot-analysis.html

Scott-Herring, M., \& Singh, S. (2017a, June 26). Development, implementation, and evaluation of a certified registered nurse anesthetist preceptorship-mentorship program. Journal of Continuing Education in Nursing, 48(10), 464-473. https://doi.org/10.3928/0022012420170918-08

Scott-Herring, M., \& Singh, S. (2017b, August). A CRNA preceptor workshop to increase preceptor satisfaction, confidence, and comfort: A quality improvement project. AANA Journal, 85(4), 24-31. https://www.aana.com/aanajournalonline

Shealy, S. C., Worrall, C. L., Baker, J. L., Grant, A. D., Fabel, P. H., Walker, C. M., Ziegler, B., \& Maxwell, W. D. (2019, September). Assessment of a faculty and preceptor development intervention to foster self-awareness and self-confidence. American Journal of Pharmaceutical Education, 83(7), 6920. https://doi.org/10.5688/ajpe6920

Sorrentino, P. (2013, September). Preceptor: blueprint for successful orientation outcomes. Journal of Emergency Nursing, 39(5), e83-e90. https://doi.org/10.1016/ j.jen.2012.05.029 
Tracy, A. (2017, December). Perceptions of certified registered nurse anesthetists on factors affecting their transition from student. AANA Journal, 85(6), 438-444. https://www. aana.com/aanajournalonline

Travis, C. (2020, September 4). Preceptor essentials. [PowerPoint slides].

Woloschuk, D. M., \& Raymond, C. B. (2012). Development and evaluation of a workplacebased preceptor training course for pharmacy practitioners. Canadian Pharmacists Journal, 145(5), 231-236. https://doi.org/10.3821/145.5.cpj231

WVU Medicine (n.d.). Mission and vision. https://wvumedicine.org/about/leadership-andmore/mission-andvision/\#: :text=Mission,care\%2C\%20research\%2C\%20and\%20 education.

Zaccagnini, M. E., \& White, K. W. (2017). The doctor of nursing practice essentials ( ${ }^{\text {rd }}$ ed.). Jones \& Bartlett Learning. 


\section{Appendix A}

\section{Budget Plan Form and Justification}

\begin{tabular}{|c|c|c|}
\hline Budget Categories & Personal Funds & $\begin{array}{c}\text { Organizational } \\
\text { Contributions }\end{array}$ \\
\hline ADMINISTRATIVE COSTS & $\$ 0$ & $\$ 0$ \\
\hline \multicolumn{3}{|c|}{$\begin{array}{l}\text { Administrative justification: The project leader will volunteer the time needed to implement. The } \\
\text { project presentation to the department will be during a regular employee meeting, this will not } \\
\text { require any additional paid time from the department. The volunteer precepting CRNAs will } \\
\text { complete the Preceptor Essentials Parts I and II modules on NetLearning during downtime at } \\
\text { work or personal time. No additional paid work time will be required of the department. }\end{array}$} \\
\hline MARKETING & $\$ 0$ & $\$ 0$ \\
\hline \multicolumn{3}{|c|}{$\begin{array}{l}\text { Marketing justification: No additional marketing plans at this time; only presentation as } \\
\text { discussed above. }\end{array}$} \\
\hline $\begin{array}{l}\text { EDUCATIONAL MATERIALS/ } \\
\text { INCENTIVES }\end{array}$ & $\$ 0$ & $\$ 0$ \\
\hline \multicolumn{3}{|c|}{$\begin{array}{l}\text { Educational Materials/Incentives justification: The intervention will be two NetLearning } \\
\text { modules, Preceptor Essentials Parts I and II. NetLearning modules are free for employees at the } \\
\text { facility of interest. Hospital employees are assigned NetLearning modules depending on their } \\
\text { job title and duties. They are completed either during free time at work or on own personal } \\
\text { time. Also, the presentation introducing the project will be completed during a regular } \\
\text { employee meeting. There should not be any additional paid time for the employees. }\end{array}$} \\
\hline $\begin{array}{l}\text { HOSPITALITY (food, room } \\
\text { rentals, etc.) }\end{array}$ & $\$ 0$ & $\$ 0$ \\
\hline \multicolumn{3}{|l|}{ Hospitality justification: N/A } \\
\hline $\begin{array}{l}\text { PROJECT SUPPLIES (office } \\
\text { supplies, postage, printing, etc.) }\end{array}$ & $\$ 0$ & $\$ 10$ \\
\hline \multicolumn{3}{|c|}{$\begin{array}{l}\text { Project supplies justification: Office supplies are not projected to exceed } \$ 10 \text { total. There may } \\
\text { be a total of } 100 \text { pages that need printed for back-up surveys, only if electronic version is not } \\
\text { available. }\end{array}$} \\
\hline TRAVEL EXPENSES & $\$ 0$ & $\$ 0$ \\
\hline \multicolumn{3}{|l|}{ Travel expenses justification: N/A } \\
\hline TOTALS & $\$ 0$ & $\$ 10$ \\
\hline
\end{tabular}


Appendix B

Simple Logic Model

\section{SIMPLE LOGIC MODEL}

- Volunteered time- project leader and participants

- Comfort and confidence in precepting adult learners- pre-training survey

- Preceptor Essentials Parts I and II modules

- Participation- CRNAS

- Improved precepting preparation and experience- post-survey 


\section{Appendix C}

\section{Implementation of a CRNA Preceptorship Training Program at an Academic Medical Center}

\begin{tabular}{|c|c|c|c|c|c|c|}
\hline $\operatorname{Aim}(s)$ & Outcomes & Objective/Criteria, AEB & \begin{tabular}{|l|} 
Target \\
Population \\
\end{tabular} & $\begin{array}{l}\text { What Data to } \\
\text { Collect }\end{array}$ & $\begin{array}{l}\text { Collection } \\
\text { Methods }\end{array}$ & $\begin{array}{l}\text { Data } \\
\text { Analysis }\end{array}$ \\
\hline $\begin{array}{l}\text {-improve } \\
\text { the } \\
\text { preceptor- } \\
\text { ship } \\
\text { experience } \\
\text { for CRNAs }\end{array}$ & $\begin{array}{l}\text {-increase comfort } \\
\text { with precepting } \\
\text {-increase } \\
\text { confidence in } \\
\text { precepting } \\
\text {-increase } \\
\text { satisfaction with } \\
\text { precepting } \\
\text { preparation }\end{array}$ & $\begin{array}{l}\text { - give a presentation to the } \\
\text { anesthesia department } \\
\text { introducing the project } \\
\text { - baseline and follow-up survey } \\
\text { completed by volunteer } \\
\text { participants } \\
\text { - volunteer precepting CRNAs } \\
\text { take the Preceptor Essentials } \\
\text { modules on NetLearning }\end{array}$ & $\begin{array}{l}\text { - CRNA } \\
\text { preceptors }\end{array}$ & $\begin{array}{l}\text { - quantitative } \\
\text { data } \\
\text { - completion } \\
\text { certificate from } \\
\text { NetLearning } \\
\text { once modules } \\
\text { completed }\end{array}$ & $\begin{array}{l}\text {-Likert } \\
\text { survey } \\
\text { - Qualtrics } \\
\text { app }\end{array}$ & $\begin{array}{l}\text {-Descriptive } \\
\text { statistics and } \\
\text { paired- } \\
\text { sample t-test } \\
\text { (SPSS) }\end{array}$ \\
\hline $\begin{array}{l}\text { - evaluate } \\
\text { the } \\
\text { usefulness } \\
\text { of the } \\
\text { Preceptor } \\
\text { Essentials } \\
\text { modules }\end{array}$ & $\begin{array}{l}\text { - satisfaction with } \\
\text { modules learning } \\
\text { content } \\
\text { - satisfaction with } \\
\text { CBL learning } \\
\text { mode (self-paced } \\
\text { and individually } \\
\text { completed) }\end{array}$ & $\begin{array}{l}\text { - follow-up survey questions } \\
\text { completed by volunteer } \\
\text { participants }\end{array}$ & $\begin{array}{l}\text { - CRNA } \\
\text { preceptors }\end{array}$ & $\begin{array}{l}\text { - qualitative and } \\
\text { quantitative } \\
\text { data }\end{array}$ & $\begin{array}{l}\text { - Likert } \\
\text { survey } \\
\text { and open- } \\
\text { ended } \\
\text { questions } \\
\text {-Qualtrics } \\
\text { app }\end{array}$ & $\begin{array}{l}\text {-Descriptive } \\
\text { statistics } \\
\text { (SPSS) }\end{array}$ \\
\hline
\end{tabular}


Appendix D

Timeline

Implementation Timeline in 2021

\begin{tabular}{|c|c|c|c|c|c|c|c|c|c|c|c|c|}
\hline & Jan & $\mathrm{Feb}$ & Mar & Apr & May & June & July & Aug & Sept & Oct & Nov & Dec \\
\hline Presentation Preparation & 1 st & 8th & & & & & & & & & & \\
\hline Introductory Presentation & & 10th & & & & & & & & & & \\
\hline Pre-training Survey & & & $1-15$ th & & & & & & & & & \\
\hline Training Intervention & & & & $1-30$ th & & & & & & & & \\
\hline Post-training Survey & & & & & 15 th & & 31 st & & & & & \\
\hline Data Analysis & & & & & & & & 1st & 15th & & & \\
\hline Manuscript and Presentation & & & & & & & & & 15 th & & & 10th \\
\hline
\end{tabular}




\section{Appendix E}

CRNA Preceptor Pre-Training Survey

\begin{tabular}{|c|c|c|c|c|c|}
\hline Please rate: & Not at all & Slightly & Somewhat & Mostly & Very much \\
\hline \multicolumn{6}{|l|}{$\begin{array}{l}\text { 1. How satisfied are you with your previous preparation } \\
\text { regarding the education of adult learners? }\end{array}$} \\
\hline \multicolumn{6}{|l|}{$\begin{array}{l}\text { 2. How confident are you with your ability to precept adult } \\
\text { learners? }\end{array}$} \\
\hline \multicolumn{6}{|l|}{$\begin{array}{l}\text { 3. How comfortable are you in actively coaching critical } \\
\text { thinking with adult learners? }\end{array}$} \\
\hline \multicolumn{6}{|l|}{$\begin{array}{l}\text { 4. How comfortable are you in working with adult learners } \\
\text { who have a different personality or learning style than } \\
\text { yours? }\end{array}$} \\
\hline \multicolumn{6}{|l|}{$\begin{array}{l}\text { 5. How confident are you in providing both positive and } \\
\text { constructive feedback to adult learners? }\end{array}$} \\
\hline \multicolumn{6}{|l|}{ 6. Have you ever had formal preceptor training? Yes/No } \\
\hline \multicolumn{6}{|l|}{$\begin{array}{l}\text { 7. How many years have you been precepting adult } \\
\text { learners? (0-5) (6-10) (11-15) (16-20) (over 20) }\end{array}$} \\
\hline $\begin{array}{l}\text { 8. What is your age? (20-29) (30-39) (40-49) (50-59) (60- } \\
69)\end{array}$ & & & & & \\
\hline
\end{tabular}

Note. Adapted from "Effect of a Preceptor Education Workshop: Part 1. Quantitative Results of a Hospital-Wide Study," by K.E. Sandau, L.G. Cheng, Z. Pan, P.R. Gaillard, and L. Hammer, 2011, The Journal of Continuing Education in Nursing, 42(3), 117-126. 


\section{Appendix F}

CRNA Preceptor Post-Training Follow-Up Survey

\begin{tabular}{|c|c|c|c|c|c|}
\hline Please rate: & Not at all & Slightly & Somewhat & Mostly & Very much \\
\hline \multicolumn{6}{|l|}{$\begin{array}{l}\text { 1. How satisfied are you with the content within the } \\
\text { Preceptor Essentials modules? }\end{array}$} \\
\hline \multicolumn{6}{|l|}{$\begin{array}{l}\text { 2. How confident are you with your ability to precept adult } \\
\text { learners? }\end{array}$} \\
\hline \multicolumn{6}{|l|}{$\begin{array}{l}\text { 3. How comfortable are you in actively coaching critical } \\
\text { thinking with adult learners? }\end{array}$} \\
\hline \multicolumn{6}{|l|}{$\begin{array}{l}\text { 4. How comfortable are you in working with adult learners } \\
\text { who have a different personality or learning style than } \\
\text { yours? }\end{array}$} \\
\hline \multicolumn{6}{|l|}{$\begin{array}{l}\text { 5. How confident are you in providing both positive and } \\
\text { constructive feedback to adult learners? }\end{array}$} \\
\hline \multicolumn{6}{|l|}{$\begin{array}{l}\text { 6. For future training, what other topics would be helpful in } \\
\text { assisting you to precept adult learners? }\end{array}$} \\
\hline \multicolumn{6}{|l|}{$\begin{array}{l}\text { 7. Were you satisfied with the mode of learning, computer- } \\
\text { based and self-paced? Yes/No }\end{array}$} \\
\hline $\begin{array}{l}\text { 8. List two things that you did like and two things that you } \\
\text { didn't like about the training? }\end{array}$ & & & & & \\
\hline
\end{tabular}

Note. Adapted from "Effect of a Preceptor Education Workshop: Part 1. Quantitative Results of a Hospital-Wide Study," by K.E. Sandau, L.G. Cheng, Z. Pan, P.R. Gaillard, and L. Hammer, 2011, The Journal of Continuing Education in Nursing, 42(3), $117-126$. 


\section{Appendix G}

\section{Results}

\section{Table 1}

Quantitative Survey Rank Results

\begin{tabular}{lccc}
\hline \multirow{2}{*}{ Satisfied with precepting preparation } & CRNA group & $\mathrm{N}$ & Mean Rank \\
\cline { 2 - 4 } & pre-training & 19 & 13.03 \\
& post-training & 11 & 19.77 \\
Confident in precepting adult learners & pre-training & 19 & 14.95 \\
& post-training & 11 & 16.45 \\
Comfortable with precepting adult learners & pre-training & 19 & 14.45 \\
& post-training & 11 & 17.32 \\
Different personality or learning style & pre-training & 19 & 14.76 \\
& post-training & 11 & 16.77 \\
Providing both positive and negative feedback & pre-training & 19 & 13.37 \\
& post-training & 11 & 19.18 \\
\hline
\end{tabular}

Note: $\mathrm{N}=$ number of respondents.

Table 2

Test Statistics

\begin{tabular}{|c|c|c|c|c|c|}
\hline & $\begin{array}{c}\text { Satisfied with } \\
\text { precepting preparation }\end{array}$ & $\begin{array}{l}\text { Confident in precepting } \\
\text { adult learners }\end{array}$ & $\begin{array}{l}\text { Comfortable with } \\
\text { precepting adult learners }\end{array}$ & $\begin{array}{c}\text { Different personality or } \\
\text { learning style }\end{array}$ & $\begin{array}{l}\text { Providing both positive } \\
\text { and negative feedback }\end{array}$ \\
\hline Mann-Whitney U & 57.500 & 94.000 & 84.500 & 90.500 & 64.000 \\
\hline Wilcoxon W & 247.500 & 284.000 & 274.500 & 280.500 & 254.000 \\
\hline Z & -2.178 & -0.483 & -0.960 & -0.664 & -1.831 \\
\hline Asymp. Sig. (2-tailed) & 0.029 & 0.629 & 0.337 & 0.507 & 0.067 \\
\hline Exact Sig. $[2 *(1$-tailed Sig. $)]$ & 0.042 & 0.672 & 0.395 & 0.553 & 0.085 \\
\hline
\end{tabular}

Note. Statistically significant results: $p \leq 0.05$. 